\title{
From antiangiogenesis to hypoxia: current research and future directions
}

\author{
This article was published in the following Dove Press journal: \\ Cancer Management and Research \\ 20 December 2010 \\ Number of times this article has been viewed
}

\author{
Christopher Rice' \\ L Eric Huang ${ }^{1,2}$ \\ 'Department of Neurosurgery, \\ ${ }^{2}$ Department of Oncological Sciences, \\ University of Utah, Salt Lake City, \\ UT, USA
}

\begin{abstract}
Angiogenesis has long been recognized as an essential element in tumor growth Since the conception of antiangiogenesis for cancer therapeutics, great strides have been made in understanding the molecular biology underlying angiogenesis, both in cancer and in physiology. By capitalizing on these advancements through bench-to-bedside research, potent antiangiogenic agents have been developed and tested. To date, the clinical results of most of these antiangiogenic agents have not met expectations. Even with the most successful agents, such as bevacizumab, used either as single agents or in combination with chemotherapy, gains in overall survival of cancer patients have been modest in most cases. In this article, the authors present the evolving views of antiangiogenic therapy, review recent experimental and clinical studies on antiangiogenesis, and address the fundamental role of hypoxia in tumor progression, which may be key to improving the efficacy of antiangiogenic therapy.
\end{abstract}

Keywords: antiangiogenesis, genetic alteration, hypoxia, tumor progression

\section{Angiogenesis, tumor growth, and antiangiogenesis}

Recognition of the association between vigorous neovascularization (angiogenesis) and tumor growth dates back to the first half of the 20th century. ${ }^{1,2}$ However, the significance of this finding and the relationship between new vessel growth and tumor growth were not fully appreciated until many years later. Folkman and others first showed that, in the absence of vascularization, tumor growth arrested when the tumor reached $2-3 \mathrm{~mm}$ in diameter, presumably owing to limited diffusion of oxygen, nutrients, and waste products. Furthermore, small, dormant tumors would quickly resume expansion when allowed to initiate neovascularization. ${ }^{3-5}$

An angiogenic factor was later isolated from human and animal tumors that is mitogenic to endothelial cells and stimulates the rapid formation of new capillaries in animals. ${ }^{6}$ Folkman proposed targeting this angiogenic factor for angiogenic inhibition as a strategy for cancer therapy, which is the fundamental premise of antiangiogenesis therapy. This unconventional approach seemed promising for several reasons. First, fewer side effects were expected from inhibiting angiogenesis than from traditional cytotoxic agents, presumably because new vessel growth in an adult patient is less important under most physiologic conditions (eg, in the absence of wound healing). Second, it seemed plausible that, in addition to restricting tumor growth to the limits of direct diffusion of nutrients and waste metabolites, reduced access to the vasculature would decrease distant metastasis. Third, by targeting the vasculature, one would expect less likelihood of developing resistance from endothelial cells than from tumor cells. ${ }^{7,8}$ 
Identifying this angiogenic factor, however, proved to be challenging. In time, it became apparent that there were many different factors involved in stimulating angiogenesis. The first to be identified was the basic fibroblast growth factor (bFGF), ${ }^{9}$ which was shown to directly stimulate endothelial cell proliferation. ${ }^{10} \mathrm{~A}$ few years later, vascular endothelial growth factor (VEGF) was identified, cloned, ${ }^{11,12}$ and characterized as a potent regulator of angiogenesis via mitogenic and antiapoptotic signaling in endothelial cells. ${ }^{13,14}$ As an increasing number of angiogenic regulators were identified and characterized, including the angiopoietins, ${ }^{15,16}$ interleukin $8,{ }^{17,18}$ and others, a more cohesive view of the mechanisms of angiogenesis in tumor growth developed.

\section{Angiogenic switch}

In 1991, Hanahan and colleagues further developed the theory that angiogenesis is required for continued tumor growth by demonstrating a switch from low to high vessel density during the multistep process of fibrosarcoma progression in transgenic mice. ${ }^{19}$ It was found that cells cultured from advanced preneoplastic lesions secreted bFGF into the growth medium, whereas cells derived from lower-grade lesions did not. This 'angiogenic switch' correlated not only with histologically higher-grade tumors but also with tumorigenicity. Similar results seen in islet cell carcinoma and epidermal squamous cell carcinoma mouse models added additional evidence to the idea that the switch to an angiogenic phenotype is a discrete step during tumor progression and essential for solid tumor growth. ${ }^{20}$

The importance of tumor angiogenesis became more apparent as the underlying mechanisms began to come into focus. Folkman's vision of developing antiangiogenic cancer therapies also began to seem within reach as interest increased. This step forward, however, did not come without hindrance.

\section{Setbacks for antiangiogenic therapy}

Despite the promising preclinical and animal model data, almost none of the early agents identified and tested have made it past clinical trials. A new use for thalidomide, which was originally introduced as a sedative and antiemetic drug, was postulated after its metabolites were found to inhibit angiogenesis in a rabbit cornea micropocket assay. ${ }^{21}$ Unfortunately, early trials showed only modest clinical effectiveness in prostate cancer patients and no antitumor activity in recurrent or metastatic squamous cell carcinoma of the head and neck. ${ }^{22,23}$
Trials of a host of other antiangiogenic drugs followed with similar results. TNP-470, an analog of fumigillin, generated only one short-lived partial response in 33 patients with metastatic renal carcinoma, ${ }^{24}$ and a later study also failed to show clinical benefit for prostate cancer. ${ }^{25}$ In two phase I clinical trials, angiostatin, which is a naturally occurring angiogenesis inhibitor, ${ }^{26}$ showed no clinical response with several types of solid tumors..$^{27,28}$ Likewise, endostatin, another natural angiogenesis inhibitor, ${ }^{29}$ showed only minor antitumor activity in a phase I trial ${ }^{30}$ and no significant tumor regression in patients with advanced neuroendocrine tumors in a phase II trial. ${ }^{31}$ In a phase II clinical trial of ABT-510, which is a peptide mimetic of thrombospondin type 1 (yet another endogenous angiogenesis inhibitor), only 3 out of 21 latestage malignant melanoma patients showed stable disease, and no definite clinical efficacy was demonstrated. ${ }^{32}$ Another phase II trial also showed only one objective response out of 88 patients with advanced soft tissue sarcoma. ${ }^{33}$

The mechanisms of action for all the previously discussed drugs are poorly or only partially understood. Agents with specific molecular targets in the angiogenic signaling pathways were explored as alternatives. This approach, however, also had several disappointments before any measure of clinical success was achieved. SU5416, which is a small synthetic receptor tyrosine kinase inhibitor of the VEGF receptor VEGFR-2, produced no objective response in 27 patients with refractory multiple myeloma. Two other phase II trials showed either no or rare responses in patients with advanced soft tissue sarcomas and recurrent head and neck cancers. ${ }^{34}$ PTK787/ZK 222584, which is another small molecule tyrosine kinase receptor inhibitor targeting all of the VEGF receptors, also failed to produce significant responses in patients with acute myeloid leukemia. ${ }^{35}$

\section{Signs of success}

In 2003, an anti-VEGF humanized monoclonal antibody, bevacizumab, made its debut with only slightly better results as a monotherapy in metastatic renal cancer patients, ${ }^{36}$ when compared with a placebo, high-dose bevacizumab had only a $10 \%$ response rate with modestly prolonged progressionfree survival but no overall survival benefit. Although these initial results were disappointing, evidence of the efficacy of bevacizumab came shortly thereafter, leading to an eventual paradigm shift in the concept of antiangiogenic therapy. In June 2004, Hurwitz et al reported a phase III trial showing substantial improvement in overall survival (about a 5-month increase) in patients with metastatic colorectal cancer when treated with bevacizumab combined with irinotecan, 
fluorouracil, and leucovorin. ${ }^{37}$ Although a handful of phase III trials involving treatment of different cancers by combining bevacizumab with various regimens have shown improvement only in progression-free survival but not overall survival, ${ }^{38-40}$ most reported studies have shown increased overall survival along with increased progression-free survival when bevacizumab is added to the treatment regimen. These include a 2-month overall survival benefit in patients with metastatic renal cell carcinoma when treated with bevacizumab in combination with interferon $\alpha-2 \mathrm{a}^{4}{ }^{41}$ in patients who had previously been treated for metastatic colorectal cancer when combined with oxaliplatin, fluorouracil, and leucovorin; $;{ }^{42}$ and in patients with non-small-cell lung cancer when combined with paclitaxel and carboplatin. ${ }^{43}$ A 3-month overall survival benefit was also reported in patients with metastatic colorectal cancer treated with bevacizumab in combination with fluorouracil and leucovorin. ${ }^{44}$ Therefore, in most cases, an apparent synergy is seen in which bevacizumab has clinical benefit when combined with cytotoxic chemotherapies.

It is also interesting to note that thalidomide, as discussed earlier, has not been proven effective as a monotherapy, but, when combined with melphalan, a cytotoxic alkylating agent, and prednisone, an immunosuppressing corticosteroid, it increases median overall survival by nearly 18 months in elderly patients with multiple myeloma, ${ }^{45}$ possibly by reducing bone marrow vascularization. ${ }^{46}$ Still, even with these first signs of success involving bevacizumab and thalidomide, tumors did become resistant relatively quickly and overall improvement was modest.

\section{Normalization of tumor vasculature}

With these clinical data has come a paradox. If antiangiogenic therapy destroys tumor vasculature, a reduction of drug delivery would be expected. Why then does antiangiogenesis enhance tumor killing when combined with cytotoxic agents? Perhaps even more puzzling is the observation that anti-VEGF therapy can increase tumor irradiation efficacy, ${ }^{47}$ which is largely dependent on tissue oxygenation.

To account for these apparently conflicting findings, Jain posited that, in addition to destroying vasculature for depriving the tumor of oxygen and nutrients, antiangiogenic agents also transiently 'normalize' the abnormal structure and function of tumor vasculature to make it more efficient for oxygen and drug delivery. ${ }^{48}$ Vasculature maintenance involves a homeostatic interplay between pro- and antiangiogenic signals. In normal tissue these signals are balanced, but during neoplastic growth the proangiogenic signals are overexpressed, thereby stimulating inappropriate vessel growth and leading to characteristically disorganized, inefficient, and leaky tumor vasculature. Jain proposed that using a low dose or 'judicious' application of antiangiogenic agents could restore the balance in the angiogenic regulation by pruning immature, nonproductive vessels, decreasing vessel permeability, and reducing abnormal dilation. The expected functional consequence of vasculature normalization is decreased interstitial fluid pressure, relieved hypoxic stress, and improved penetration of drugs in the tumor.

Although vasculature normalization has been shown to improve vascular function in preclinical models through intravital imaging studies, ${ }^{49}$ it is not straightforward to ascertain in patients the changes in blood flow and distribution within a tumor during antiangiogenic therapy, making it difficult to verify this process. Many questions, such as why there is only a transient 'normalization window' and how to identify it, remain unanswered.

\section{Negative sequelae of targeting tumor vasculature}

As mentioned earlier, a potential advantage of targeting endothelial rather than tumor cells is the avoidance of drug resistance, because endothelial cells, unlike those of tumors, are genetically stable. ${ }^{7}$ However, tumor revascularization following a transient decrease in vessel density with an antiVEGF receptor agent has been reported, resulting at least in part from increased levels of bFGF. ${ }^{50}$

It has become increasingly clear that VEGF-targeted therapy probably involves multiple mechanisms. ${ }^{51} \mathrm{~A}$ possible explanation for the activation of alternative angiogenic pathways, however, is that antiangiogenesis induces hypoxia, resulting in activation of the hypoxia-inducible factor $\alpha(\mathrm{HIF}-\alpha)$, which in turn triggers revascularization of the tumor. HIF- $\alpha$ is known to transcriptionally upregulate a host of pro- and antiangiogenic genes encoding placental growth factor, angiopoietin 1, angiopoietin 2, stromal-derived factor 1, platelet-derived growth factor, and bFGF, as well as VEGF. ${ }^{52}$ Given that overexpression of HIF- $1 \alpha$, one of the HIF- $\alpha$ family members (see below), induces nonleaky hypervascularity in transgenic mice, ${ }^{53}$ it is conceivable that activated HIF- $\alpha$ could upregulate both pro- and antiangiogenic factors for neovascularization in tumors. Indeed, mice haplodeficient in $E g \ln 1$, which encodes a negative regulator of HIF- $\alpha$ (see below), showed normalized endothelial lining and vessel maturation, thereby resulting in improved tumor oxygenation with decreased tumor invasiveness, even though tumor growth was not inhibited..$^{54}$ 
Irrespective of vasculature regression and/or normalization, a more serious concern with antiangiogenic therapy is that vessel regression may drive tumors toward a more locally invasive and distantly metastatic phenotype. Indeed, increased invasiveness in glioblastoma models was observed after systemic antiangiogenic therapy with an antibody against VEGFR-2, despite a marked inhibition of tumor growth and microvessel density. ${ }^{55,56}$ Similar results were seen after treatment with bevacizumab in another glioblastoma preclinical study. ${ }^{57}$ In addition, increased invasiveness after anti-VEGFR-2 treatment was also seen in a pancreatic neuroendocrine cancer mouse model, along with increased liver and lymph node metastases. ${ }^{58}$ Furthermore, short-term treatment with a potent angiogenic inhibitor, sunitinib/SU11248, also accelerated metastasis into multiple organs in a preclinical study using breast cancer and melanoma cells. ${ }^{59}$ More troubling is that the invasive nature of the tumors seemed to be permanently established, as removal of treatment did not relieve the aggressive phenotype, possibly suggesting a genetic transformation. Although this increased invasiveness in response to antiangiogenic therapy has not been unequivocally confirmed in patients, partially because of imaging limitations in evaluating these tumors (ie, FLAIR magnetic resonance imaging), it has nonetheless been observed at least subjectively. ${ }^{60} \mathrm{~A}$ review of literature indicates that although glioblastoma patients benefit greatly from reduced cerebral edema and intracranial pressure through angiogenic inhibition, tumor invasion continues. ${ }^{61}$ Additional concerns include that the normalization of tumor vasculature by antiangiogenic agents may restore the blood-brain barrier function, thereby antagonizing the efficacy of chemotherapeutic drugs.

\section{HIF-I $\alpha$, genetic alteration, and tumor progression}

Hypoxia has long been implicated in genetic instability and tumor progression, which may account for the inevitable failure of antiangiogenesis as a monotherapy. Although the mechanisms underlying hypoxia-induced tumor progression remain to be elucidated, recent evidence indicates that HIF- $\alpha$ plays an essential role in tumor growth and progression.

In human cancers, both HIF-1 $\alpha$ and HIF-2 $\alpha$, two of the prevalent members of the HIF- $\alpha$ family, are frequently dysregulated, resulting in their overexpression. ${ }^{62}$ Under physiological conditions when oxygen tension within cells is high, HIF- $\alpha$ is hydroxylated at specific proline residues by the prolyl hydroxylases EGLN1, EGLN2, and EGLN3 (better known as PHD2, PHD1, and PHD3, respectively). ${ }^{63,64}$
This allows HIF- $\alpha$ to be ubiquitinated by a pVHL-directed E3 ligase and targeted to the proteasome for degradation. In hypoxia, however, the hydroxylation reaction is inhibited; HIF- $\alpha$ accumulates within the cell, translocates to the nucleus, and, upon dimerization with its binding partner aryl hydrocarbon receptor nuclear translocator (ARNT), acts as a transcription factor for the activation of a diverse group of hypoxia-responsive genes. ${ }^{52}$ This canonical HIF- $\alpha-$ ARNT pathway (Figure 1) has accounted for hypoxic activation of many genes directly related to tumor growth and survival, such as those involved in glycolysis, cell migration, apoptosis, multidrug resistance, extracellular matrix modification, epithelial-mesenchymal transition, and angiogenesis. ${ }^{62,65}$

Despite these extraordinary insights into the mechanisms underlying tumor biology, how hypoxia drives genetic alteration, the underlying cause of tumor progression, has yet to be elucidated. ${ }^{66,67}$ Interestingly, we and others began to show recently that HIF- $1 \alpha$ and HIF- $2 \alpha$ have opposing effects on DNA repair; HIF- $1 \alpha$ inhibits, whereas HIF- $2 \alpha$ stimulates, DNA repair. ${ }^{68,69}$ Although how these conflicting effects between HIF- $1 \alpha$ and HIF-2 $\alpha$ are reconciled within tumor cells needs further investigation, our results demonstrated that HIF-1 $\alpha$, but not HIF- $2 \alpha$, is essential to hypoxic downregulation of the DNA mismatch repair genes $\mathrm{MSH} 2$ and $\mathrm{MSH}^{70}$ and the double-strand break repair gene $N B N .{ }^{71}$ Interestingly, HIF-1 $\alpha$ does so by a distinct mechanism that is independent of the HIF-1 $\alpha$-ARNT pathway but involves HIF-1 $\alpha$ func-

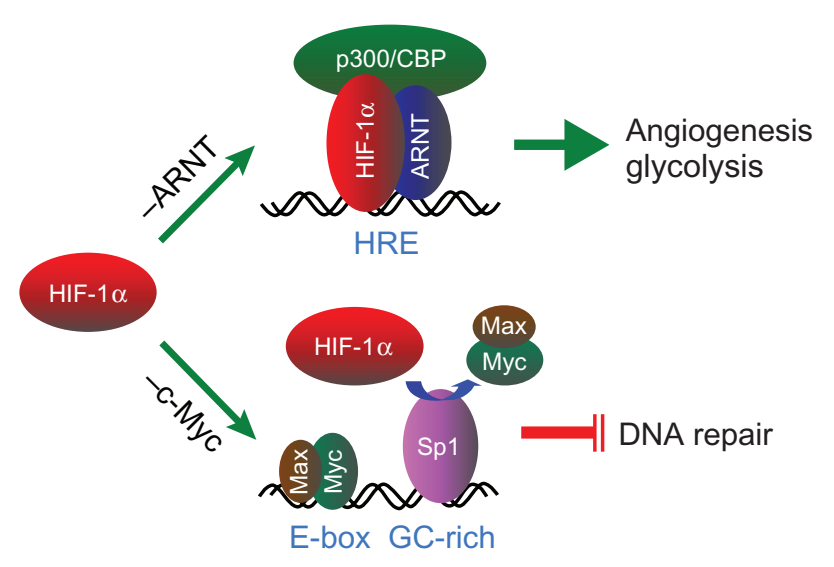

Figure I A schematic representation of the HIF-I $\alpha-A R N T$ pathway and the HIF-I $\alpha$-c-Myc pathway. Stabilized HIF-I $\alpha$ participates in the canonical HIF-I $\alpha-$ ARNT pathway (-ARNT) through dimerization with its binding partner ARNT, recruitment of the transcription coactivator $\mathrm{p} 300 / \mathrm{CBP}$, and binding to the HRE in the promoter of the angiogenic and glycolytic genes for transcriptional activation. Alternatively, the HIF-I $\alpha-c-M y c$ pathway (-c-Myc) involves HIF-I $\alpha$ competing with c-Myc for binding to the transcription factor $\mathrm{Spl}$ in the promoter of DNA repair genes, resulting in selective c-Myc displacement and gene repression.

Abbreviations: HIF, hypoxia-inducible factor; ARNT, aryl hydrocarbon receptor nuclear translocator; HRE, hypoxia-responsive element. 
tionally counteracting c-Myc, a transcriptional activator for maintaining DNA repair gene expression. This HIF-1 $\alpha-\mathrm{c}-$ Myc pathway ${ }^{72}$ accounts not only for hypoxic inhibition of DNA repair but also for resultant DNA damage and genetic alterations (Figure 1). By uncoupling these two distinct, independent pathways of HIF-1 $\alpha$, we have recently shown that the HIF-1 $\alpha-$-c-Myc pathway is essential to drive tumor progression, whereas the HIF-1 $\alpha$-ARNT pathway is more involved in tumor growth. ${ }^{73}$ Therefore, the dual functions of HIF-1 $\alpha$ may account on the one hand for vasculature normalization resulting from regulated expression of both pro- and antiangiogenic genes via the HIF- $1 \alpha-$ ARNT pathway, and on the other hand for tumor progression driven by genetic alterations via the HIF-1 $\alpha-\mathrm{c}-\mathrm{Myc}$ pathway.

With this gained knowledge, we propose that in addition to its important role in angiogenesis and glycolysis for tumor growth and survival, HIF-1 $\alpha$ is essential to drive genetic alteration for tumor progression, which is a negative aspect of the hypoxic response ${ }^{74}$ enabling tumor cells to evolve through increased genetic heterogeneity. This could explain the ease with which many cancers are able to adapt to a wide variety of therapeutics (including antiangiogenics) and develop resistance. It could also explain the apparent genetic changes that lead to increased invasion and metastasis in antiangiogenic-treated tumors.

\section{Future directions of antiangiogenic therapy}

Although antiangiogenic therapy remains promising, ${ }^{51}$ a durable antitumor activity for an improved overall survival is desired. To this end, several hypotheses have been proposed. Pietras and Hanahan suggested the use of broader-spectrum angiogenesis inhibitors or 'cocktails' of specific inhibitors as a method of blocking alternative angiogenic pathways that may be activated under a VEGF blockade. ${ }^{75}$ They have demonstrated the efficacy of this tactic in an animal model of islet cell carcinogenesis. Treatment with anti-VEGFR-2 antibodies led to an initial decrease in tumor vascularity as well as tumor size. This was followed by revascularization and regrowth of the tumors. Greater response was seen, however, by coinhibiting bFGF, which was suspected in an alternative angiogenic pathway. This resulted in a further decrease in tumor growth after the initial regression.

On the other hand, it stands to reason that if HIF- $\alpha$ can be targeted alongside antiangiogenic agents to prevent the induction of genetic alteration and/or angiogenesis, this could greatly improve the efficacy of antiangiogenic therapy. Interestingly, Melillo and Rapisarda et al have identified a potential HIF- $\alpha$ inhibitor, topotecan. ${ }^{76,77}$ When used alongside bevacizumab in U251 glioma xenografts, topotecan showed considerable synergistic antitumor activity. Not only was tumor volume decreased but intratumor vasculature was also decreased compared with tumors treated with either topotecan or bevacizumab alone. ${ }^{78}$ Considering the increased invasive nature of tumors following antiangiogenic treatment, HIF- $\alpha$ targeting may prove to be an effective way of maximizing antiangiogenic therapy in the future. Likewise, drugs that potentially block genetic alteration and thereby tumor progression may greatly improve overall survival when combined with antiangiogenic agents.

\section{Conclusions}

Antiangiogenic therapy was initially based on the notion that angiogenesis is required for tumor growth, and thus

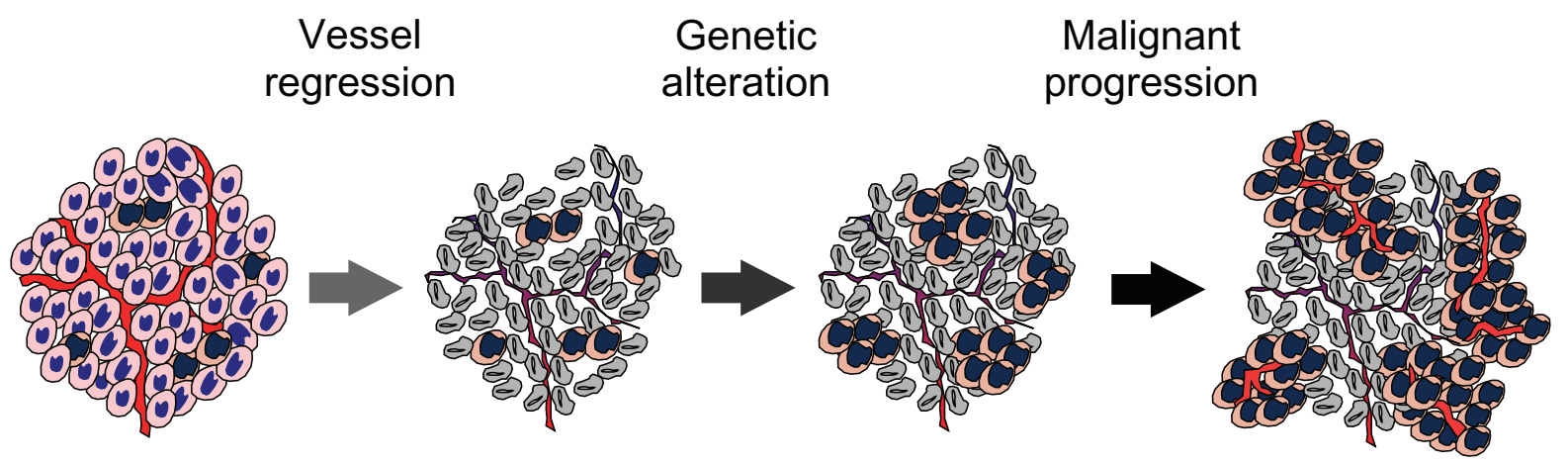

Figure 2 A hypothetic model illustrates that malignant progression results from antiangiogenic therapy. Angiogenic inhibition deprives tumor cells of oxygen and nutrients, resulting in vessel regression and thereby death of the majority of the tumor cells. However, hypoxic cells harbored within the solid tumor are able to tolerate severe hypoxia by undergoing genetic alterations for malignant progression via the HIF-I $\alpha$-c-Myc pathway and by inducing angiogenesis and glycolysis for cell proliferation via the HIF-I $\alpha-A R N T$ pathway.

Abbreviations: HIF, hypoxia-inducible factor; ARNT, aryl hydrocarbon receptor nuclear translocator. 
destruction of the tumor vasculature would deprive the tumor of oxygen and nutrients, resulting in growth inhibition. However, tumor vasculature is structurally abnormal and functionally inefficient, and the resultant hypoxic microenvironment is associated with tumor progression and resistance to therapies (Figure 2). Therefore, therapeutic destruction of the tumor vasculature is expected to yield more severe hypoxia, which on the one hand induces additional angiogenic responses through the activation of HIF- $\alpha$ for normalizing vasculature, and on the other hand drives genetic alteration for malignant progression. This view accounts for the unexpected clinical outcomes when single antiangiogenesis agents are used, some clinical benefits when antiangiogenesis agents are used in combination with chemotherapy, and fundamentally the inevitable problem of angiogenic therapy, which is that hypoxia promotes tumor progression. Thus, targeting tumor hypoxia may improve the efficacy of angiogenic therapy.

\section{Acknowledgments}

We thank Kristin Kraus for editing the manuscript. LEH was supported in part by a Public Health Service grant (CA-131355) from the National Cancer Institute, and CR was supported by a Public Health Service grant (HL-007744) from the National Institute of Diabetes and Digestive and Kidney Diseases.

\section{Disclosure}

The authors report no conflicts of interest in this work.

\section{References}

1. Ide AG, Baker NH, Warren SL. Vascularization of the Brown-Pearce rabbit epithelioma transplant as seen in the transparent ear chamber. AJR Am J Roentgenol. 1939;42:891-899.

2. Algire GH, Chalkley HW. Vascular reactions of normal and malignant tissues in vivo. I. Vascular reactions of mice to wounds and to normal and neoplastic transplants. J Natl Cancer Inst. 1945;6:73-85.

3. Greene HS. Heterologous transplantation of mammalian tumors: I. The transfer of rabbit tumors to alien species. J Exp Med. 1941;73(4): 461-474.

4. Folkman J, Cole P, Zimmerman S. Tumor behavior in isolated perfused organs: in vitro growth and metastases of biopsy material in rabbit thyroid and canine intestinal segment. Ann Surg. 1966;164(3):491-502.

5. Gimbrone MA, Aster RH, Cotran RS, Corkery J, Jandl JH, Folkman J. Preservation of vascular integrity in organs perfused in vitro with a platelet-rich medium. Nature. 1969;222(5188):33-36.

6. Folkman J. Tumor angiogenesis: therapeutic implications. N Engl J Med. 1971;285(21):1182-1186.

7. Boehm T, Folkman J, Browder T, O’Reilly MS. Antiangiogenic therapy of experimental cancer does not induce acquired drug resistance. Nature. 1997;390(6658):404-407.

8. Folkman J. Seminars in medicine of the Beth Israel Hospital, Boston. Clinical applications of research on angiogenesis. N Engl J Med. 1995; 333(26):1757-1763.
9. Shing Y, Folkman J, Sullivan R, Butterfield C, Murray J, Klagsbrun M. Heparin affinity: purification of a tumor-derived capillary endothelial cell growth factor. Science. 1984;223(4642):1296-1299.

10. Folkman J, Klagsbrun M. Angiogenic factors. Science. 1987;235(4787): 442-447.

11. Keck PJ, Hauser SD, Krivi G, et al. Vascular permeability factor, an endothelial cell mitogen related to PDGF. Science. 1989;246(4935): 1309-1312.

12. Leung DW, Cachianes G, Kuang WJ, Goeddel DV, Ferrara N. Vascular endothelial growth factor is a secreted angiogenic mitogen. Science. 1989;246(4935):1306-1309.

13. Alon T, Hemo I, Itin A, Pe'er J, Stone J, Keshet E. Vascular endothelial growth factor acts as a survival factor for newly formed retinal vessels and has implications for retinopathy of prematurity. Nat Med. 1995; 1(10):1024-1028.

14. Ferrara N, Davis-Smyth T. The biology of vascular endothelial growth factor. Endocr Rev. 1997;18(1):4-25.

15. Davis $\mathrm{S}$, Aldrich TH, Jones PF, et al. Isolation of angiopoietin-1, a ligand for the TIE2 receptor, by secretion-trap expression cloning. Cell. 1996;87(7):1161-1169.

16. Holash J, Maisonpierre PC, Compton D, et al. Vessel cooption, regression, and growth in tumors mediated by angiopoietins and VEGF. Science. 1999;284(5422):1994-1998.

17. Koch AE, Polverini PJ, Kunkel SL, et al. Interleukin-8 as a macrophage-derived mediator of angiogenesis. Science. 1992;258(5089): 1798-1801.

18. Strieter RM, Kunkel SL, Elner VM, et al. Interleukin-8. A corneal factor that induces neovascularization. Am J Pathol. 1992;141(6): 1279-1284.

19. Kandel J, Bossy-Wetzel E, Radvanyi F, Klagsbrun M, Folkman J, Hanahan D. Neovascularization is associated with a switch to the export of bFGF in the multistep development of fibrosarcoma. Cell. 1991; 66(6):1095-1104.

20. Hanahan D, Folkman J. Patterns and emerging mechanisms of the angiogenic switch during tumorigenesis. Cell. 1996;86(3):353-364.

21. D'Amato RJ, Loughnan MS, Flynn E, Folkman J. Thalidomide is an inhibitor of angiogenesis. Proc Natl Acad Sci U S A. 1994;91(9): 4082-4085.

22. Tseng JE, Glisson BS, Khuri FR, et al. Phase II study of the antiangiogenesis agent thalidomide in recurrent or metastatic squamous cell carcinoma of the head and neck. Cancer. 2001;92(9):2364-2373.

23. Figg WD, Dahut W, Duray P, et al. A randomized phase II trial of thalidomide, an angiogenesis inhibitor, in patients with androgenindependent prostate cancer. Clin Cancer Res. 2001;7(7):1888-1893.

24. Stadler WM, Kuzel T, Shapiro C, Sosman J, Clark J, Vogelzang NJ. Multi-institutional study of the angiogenesis inhibitor TNP-470 in metastatic renal carcinoma. J Clin Oncol. 1999;17(8):2541-2545.

25. Logothetis CJ, Wu KK, Finn LD, et al. Phase I trial of the angiogenesis inhibitor TNP-470 for progressive androgen-independent prostate cancer. Clin Cancer Res. 2001;7(5):1198-1203.

26. O’Reilly MS, Holmgren L, Shing Y, et al. Angiostatin: a novel angiogenesis inhibitor that mediates the suppression of metastases by a Lewis lung carcinoma. Cell. 1994;79(2):315-328.

27. Beerepoot LV, Witteveen EO, Groenewegen G, et al. Recombinant human angiostatin by twice-daily subcutaneous injection in advanced cancer: a pharmacokinetic and long-term safety study. Clin Cancer Res. 2003;9(11):4025-4033.

28. Soff GA, Wang H, Cundiff DL, et al. In vivo generation of angiostatin isoforms by administration of a plasminogen activator and a free sulfhydryl donor: a phase I study of an angiostatic cocktail of tissue plasminogen activator and mesna. Clin Cancer Res. 2005;11(17): 6218-6225.

29. O'Reilly MS, Boehm T, Shing Y, et al. Endostatin: an endogenous inhibitor of angiogenesis and tumor growth. Cell. 1997;88(2): 277-285. 
30. Herbst RS, Hess KR, Tran HT, et al. Phase I study of recombinant human endostatin in patients with advanced solid tumors. J Clin Oncol. 2002;20(18):3792-3803.

31. Kulke MH, Bergsland EK, Ryan DP, et al. Phase II study of recombinant human endostatin in patients with advanced neuroendocrine tumors. J Clin Oncol. 2006;24(22):3555-3561.

32. Markovic SN, Suman VJ, Rao RA, et al. A phase II study of ABT-510 (thrombospondin-1 analog) for the treatment of metastatic melanoma. Am J Clin Oncol. 2007;30(3):303-309.

33. Baker LH, Rowinsky EK, Mendelson D, et al. Randomized, phase II study of the thrombospondin-1-mimetic angiogenesis inhibitor ABT-510 in patients with advanced soft tissue sarcoma. J Clin Oncol. 2008;26(34):5583-5588.

34. Fury MG, Zahalsky A, Wong R, et al. A phase II study of SU5416 in patients with advanced or recurrent head and neck cancers. Invest New Drugs. 2007;25(2):165-172.

35. Roboz GJ, Giles FJ, List AF, et al. Phase 1study of PTK787/ZK 222584, a small molecule tyrosine kinase receptor inhibitor, for the treatment of acute myeloid leukemia and myelodysplastic syndrome. Leukemia 2006;20(6):952-957.

36. Yang JC, Haworth L, Sherry RM, et al. A randomized trial of bevacizumab, an anti-vascular endothelial growth factor antibody, for metastatic renal cancer. $N$ Engl J Med. 2003;349(5):427-434.

37. Hurwitz H, Fehrenbacher L, Novotny W, et al. Bevacizumab plus irinotecan, fluorouracil, and leucovorin for metastatic colorectal cancer. N Engl J Med. 2004;350(23):2335-2342.

38. van Cutsem E, Vervenne WL, Bennouna J, et al. Phase III trial of bevacizumab in combination with gemcitabine and erlotinib in patients with metastatic pancreatic cancer. J Clin Oncol. 2009;27(13):2231-2237.

39. Saltz LB, Clarke S, Diaz-Rubio E, et al. Bevacizumab in combination with oxaliplatin-based chemotherapy as first-line therapy in metastatic colorectal cancer: a randomized phase III study. J Clin Oncol. 2008;26(12):2013-2019.

40. Miller K, Wang M, Gralow J, et al. Paclitaxel plus bevacizumab versus paclitaxel alone for metastatic breast cancer. $N$ Engl J Med. 2007;357(26):2666-2676.

41. Escudier B, Bellmunt J, Negrier S, et al. Phase III trial of bevacizumab plus interferon alfa-2a in patients with metastatic renal cell carcinoma (AVOREN): final analysis of overall survival. J Clin Oncol. 2010;28(13):2144-2150.

42. Giantonio BJ, Catalano PJ, Meropol NJ, et al. Bevacizumab in combination with oxaliplatin, fluorouracil, and leucovorin (FOLFOX4) for previously treated metastatic colorectal cancer: results from the Eastern Cooperative Oncology Group Study E3200. J Clin Oncol. 2007;25(12):1539-1544.

43. Sandler A, Gray R, Perry MC, et al. Paclitaxel-carboplatin alone or with bevacizumab for non-small-cell lung cancer. $N$ Engl J Med. 2006;355(24):2542-2550.

44. Kabbinavar FF, Hambleton J, Mass RD, Hurwitz HI, Bergsland E, Sarkar S. Combined analysis of efficacy: the addition of bevacizumab to fluorouracil/leucovorin improves survival for patients with metastatic colorectal cancer. J Clin Oncol. 2005;23(16):3706-3712.

45. Facon T, Mary JY, Hulin C, et al. Melphalan and prednisone plus thalidomide versus melphalan and prednisone alone or reducedintensity autologous stem cell transplantation in elderly patients with multiple myeloma (IFM 99-06): a randomised trial. Lancet. 2007; 370(9594):1209-1218.

46. Singhal S, Mehta J, Desikan R, et al. Antitumor activity of thalidomide in refractory multiple myeloma. $N$ Engl J Med. 1999;341(21): 1565-1571.

47. Lee CG, Heijn M, di Tomaso E, et al. Anti-vascular endothelial growth factor treatment augments tumor radiation response under normoxic or hypoxic conditions. Cancer Res. 2000;60(19):5565-5570.

48. Jain RK. Normalization of tumor vasculature: an emerging concept in antiangiogenic therapy. Science. 2005;307(5706):58-62.
49. Fukumura D, Duda DG, Munn LL, Jain RK. Tumor microvasculature and microenvironment: novel insights through intravital imaging in pre-clinical models. Microcirculation. 2010;17(3):206-225.

50. Casanovas O, Hicklin DJ, Bergers G, Hanahan D. Drug resistance by evasion of antiangiogenic targeting of VEGF signaling in late-stage pancreatic islet tumors. Cancer Cell. 2005;8(4):299-309.

51. Ellis LM, Hicklin DJ. VEGF-targeted therapy: mechanisms of antitumour activity. Nat Rev Cancer. 2008;8(8):579-591.

52. Semenza GL. Targeting HIF-1 for cancer therapy. Nat Rev Cancer. 2003;3(10):721-732.

53. Elson DA, Thurston G, Huang LE, et al. Induction of hypervascularity without leakage or inflammation in transgenic mice overexpressing hypoxia-inducible factor-1alpha. Genes Dev. 2001;15(19): 2520-2532.

54. Mazzone M, Dettori D, Leite de Oliveira R, et al. Heterozygous deficiency of PHD2 restores tumor oxygenation and inhibits metastasis via endothelial normalization. Cell. 2009;136(5):839-851.

55. Lamszus K, Kunkel P, Westphal M. Invasion as limitation to antiangiogenic glioma therapy. Acta Neurochir Suppl. 2003;88:169-177.

56. Bergers G, Hanahan D. Modes of resistance to anti-angiogenic therapy Nat Rev Cancer. 2008;8(8):592-603.

57. Lucio-Eterovic AK, Piao Y, de Groot JF. Mediators of glioblastoma resistance and invasion during antivascular endothelial growth factor therapy. Clin Cancer Res. 2009;15(14):4589-4599.

58. Paez-Ribes M, Allen E, Hudock J, et al. Antiangiogenic therapy elicits malignant progression of tumors to increased local invasion and distant metastasis. Cancer Cell. 2009;15(3):220-231.

59. Ebos JM, Lee CR, Cruz-Munoz W, Bjarnason GA, Christensen JG, Kerbel RS. Accelerated metastasis after short-term treatment with a potent inhibitor of tumor angiogenesis. Cancer Cell. 2009;15(3): 232-239.

60. Norden AD, Young GS, Setayesh K, et al. Bevacizumab for recurrent malignant gliomas: efficacy, toxicity, and patterns of recurrence. Neurology. 2008;70(10):779-787.

61. Verhoeff JJ, van Tellingen O, Claes A, et al. Concerns about antiangiogenic treatment in patients with glioblastoma multiforme. $B M C$ Cancer. 2009;9:444.

62. Bertout JA, Patel SA, Simon MC. The impact of $\mathrm{O}_{2}$ availability on human cancer. Nat Rev Cancer. 2008;8(12):967-975.

63. Huang LE, Bunn HF. Hypoxia-inducible factor and its biomedical relevance. J Biol Chem. 2003;278(22):19575-19578.

64. Kaelin WG Jr, Ratcliffe PJ. Oxygen sensing by metazoans: the central role of the HIF hydroxylase pathway. Mol Cell. 2008;30(4): 393-402.

65. Harris AL. Hypoxia - a key regulatory factor in tumour growth. Nat Rev Cancer. 2002;2(1):38-47.

66. Huang LE, Bindra RS, Glazer PM, Harris AL. Hypoxia-induced genetic instability - a calculated mechanism underlying tumor progression. J Mol Med. 2007;85(2):139-148.

67. Bristow RG, Hill RP. Hypoxia and metabolism. Hypoxia, DNA repair and genetic instability. Nat Rev Cancer. 2008;8(3):180-192.

68. Huang LE. Carrot and stick: HIF-alpha engages c-Myc in hypoxic adaptation. Cell Death Differ. 2008(4);15:672-677.

69. Gordan JD, Lal P, Dondeti VR, et al. HIF-alpha effects on c-Myc distinguish two subtypes of sporadic VHL-deficient clear cell renal carcinoma. Cancer Cell. 2008;14(6):435-446.

70. Koshiji M, To KK, Hammer S, et al. HIF-1alpha induces genetic instability by transcriptionally downregulating MutSalpha expression. Mol Cell. 2005;17(6):793-803.

71. To KK, Sedelnikova OA, Samons M, Bonner WM, Huang LE. The phosphorylation status of PAS-B distinguishes HIF-1alpha from HIF-2alpha in NBS1 repression. EMBO J. 2006;25(20):4784-4794.

72. Koshiji M, Kageyama Y, Pete EA, Horikawa I, Barrett JC, Huang LE. HIF-1alpha induces cell cycle arrest by functionally counteracting Myc. EMBO J. 2004;23(9):1949-1956. 
73. Yoo YG, Christensen J, Huang LE. HIF-1 $\alpha$ confers aggressive malignant traits on human tumor cells independent of its canonical transcriptional function. Cancer Res. (In press).

74. To KK, Koshiji M, Hammer S, Huang LE. Genetic instability: the dark side of the hypoxic response. Cell Cycle. 2005;4(7):881-882.

75. Pietras K, Hanahan D. A multitargeted, metronomic, and maximumtolerated dose 'chemo-switch' regimen is antiangiogenic, producing objective responses and survival benefit in a mouse model of cancer. J Clin Oncol. 2005;23(5):939-952.
76. Melillo G. Inhibiting hypoxia-inducible factor 1 for cancer therapy. Mol Cancer Res. 2006;4(9):601-605.

77. Rapisarda A, Uranchimeg B, Sordet O, Pommier Y, Shoemaker RH, Melillo G. Topoisomerase I-mediated inhibition of hypoxia-inducible factor 1: mechanism and therapeutic implications. Cancer Res. 2004;64(4):1475-1482.

78. Rapisarda A, Hollingshead M, Uranchimeg B, et al. Increased antitumor activity of bevacizumab in combination with hypoxia inducible factor-1 inhibition. Mol Cancer Ther. 2009;8(7):1867-1877.

\section{Publish your work in this journal}

Cancer Management and Research is an international, peer-reviewed open access journal focusing on cancer research and the optimal use of preventative and integrated treatment interventions to achieve improved outcomes, enhanced survival and quality of life for the cancer patient. The journal welcomes original research, clinical \& epidemiological studies, reviews \& evaluations, guidelines, expert opinion \& commentary, case reports \& extended reports. The manuscript management system is completely online and includes a very quick and fair peerreview system, which is all easy to use. Visit http://www.dovepress.com/ testimonials.php to read real quotes from published authors.

Submit your manuscript here: http://www.dovepress.com/cancer-management-and-research-journal 